\title{
Early In-hospital Management of Acute Ischemic Stroke
}

\author{
Sang-Hoon Lee, Kyung-Jae Park, Dong-Hyuk Park, Shin-Hyuk Kang, Yong-Gu Jung, Jung-Yul Park
}

Department of Neurosurgery, Korea University Medical Center, Korea University College of Medicine, Seoul, Korea

Received: March 24, 2019

Accepted: April 1, 2019

Corresponding Author:

Sang-Hoon Lee, M.D.,

Department of Neurosurgery,

Korea University Medical Center,

Anam Hospital, Korea University

College of Medicine, 73 Inchonro

Sungbuk-gu, Seoul 02841, Korea

Tel: +82-2-920-5729

Fax: +82-2-929-0629

E-mail: pibada106@hanmail.net
Acute ischemic stroke is one of leading causes of disability worldwide. Current therapeutic modalities have very narrow time window, therefore adequate diagnosis and therapeutic modality choice is very important. This article highlights the issues regarding current recommendation of early in-hospital management of acute ischemic stroke. By understanding current recommendation of treatment, we can better access and treat patients with acute ischemic stroke.

Keywords: Ischemic stroke; Alteplase; Thrombectomy

\section{INTRODUCTION}

Acute ischemic stroke(AIS) is one of the most frequent causes of disability and death worldwide ${ }^{6,16)}$, and enormous social and financial cost due to rehabilitation, long-term care, and loss of productivity ${ }^{17)}$. Leading-therapeutic modalities, include intravenous(IV) thrombolysis and mechanical thrombectomy is extremely time-dependent. Therefore, proper early diagnosis and management is very important. As the reason above, pre-hospital stroke service is one of major concerns of treatment, includes emergency medical services(EMS) and pre-stroke education $^{13,18)}$. Distance and travel time to the nearest stroke center is a crucial issue for time-sensitive stroke treatment ${ }^{5,13)}$.

As mentioned above, current therapeutic modalities have very narrow time window. The phrase "time is brain" ${ }^{\text {") }}$ presents the importance of urgent medical service for patients with stroke. However, as clinical data accumulated, this narrow time window has been expanded and therapeutic modalities have been changed over periods ${ }^{1,15,22,28)}$, although primary "time is brain" motto remains unchanged. In this article, the focus is on the current in-hospital management recommendation of diagnosis of AIS and early therapeutic modalities with review of modification from previous guidelines, helps improving clinical outcomes of stroke patients.

\section{EARLY IN-HOSPITAL MANAGEMENT OF ACUTE ISCHEMIC STROKE}

\section{Evaluation}

After patient's arrival on emergency room, use of standardized scale quantifies the degree of neurological deficit, facilitates communication, helps identify patients for thrombolytic intervention is required ${ }^{18)}$. Most preferred rating scale is National Institutes of Health Stroke Scale ${ }^{12)}$ (NIHSS, Table 1). Score represents severity of stoke; 0 : no stroke symptom ; $1-4$ : minor stroke ; 5-15 : moderate stroke ; $16-20$ : moderate to severe stroke ; $21-42$ : severe stroke.

Copyright (C) 2019 The Korean Neurointensive Care Society

This is an Open Access article distributed under the terms of the Creative Commons Attribution Non-Commercial License (http://creativecommons.org/licenses/by-nc/4.0/) which permits unrestricted non-commercial use, distribution, and reproduction in any medium, provided the original work is properly cited. 
Table 1. National institutes of health stroke scale (NIHSS)

\begin{tabular}{lll}
\hline $\begin{array}{l}\text { Tested } \\
\text { Item }\end{array}$ & \multicolumn{1}{c}{ Title } & \multicolumn{1}{c}{ Responses and Scores } \\
\hline 1A $\quad$ Level of consciousness & 0 - Alert \\
& & 1 - Drowsy \\
& 2 - Obtunded \\
& & 3 - Coma / Unresponsive \\
& & 0 - Answers both correctly \\
1B $\quad$ Orientation question (2) & 1 - Answers 1 correctly \\
& & $2-$ Answers neither correctly
\end{tabular}

$1 \mathrm{C}$

Response to command 0 - Performs both tasks correctly (2)

$2 \quad$ Gaze

Visual fields

Facial movement

0 - Normal

1 - Minor facial weakness

2 - Partial facial weakness

3 - Complete unilateral palsy

5

Motor function (arm) $\quad 0$ - No drift

a. Left

1 - Drift before 10 seconds

b. Right

6

Motor function (leg) $\quad 0$ - No drift

a. Left

b. Right

1 - Ataxia in 1 limb

2 - Ataxia in 2 limbs

8 Sensory

Language

0 - No sensory loss

1 - Mild sensory loss

2 - Severe sensory loss

0 - Normal

1 - Mild aphasia

2 - Severe aphasia

3 - Mute or global aphasia

10

Articulation

0 - Normal

1 - Mild dysarthria

2 - Severe dysarthria

11

Extinction or inattention 0 - Absent

1 - Mild loss ( 1 sensory modality lost)

2 - Severe loss (2 modalities lost)
After exam of NIHSS, proper brain imaging should be followed. All patients admitted to hospital with suspected acute stroke should receive brain imaging evaluation on arrival ${ }^{18)}$. In most cases, non-contrast computed tomography(NCCT) is recommended ${ }^{2,18,21)}$. Although diffusion-weighted magnetic resonance imaging(DW-MRI) is more sensitive than NCCT for detecting $\mathrm{AIS}^{3,11)}$, routine use of DW-MRI is not recommended due to the matter of cost-effectiveness ${ }^{18,24)}$. In many cases, diagnosis of AIS is confirmed basis of clinical presentation either a negative NCCT (or show early ischemic change). DW-MRI is recommended when NCCT is negative and patients shows puzzling clinical presentation or uncertain clinical stroke localization ${ }^{18)}$. Powers et al. recommends imaging study should be performed within 20 minutes $^{14,18)}$ of arrival in ER. In some institutions, DW-MRI is routinely performed before IV alteplase administration even if diagnosis of acute stroke was established with NCCT and clinical presentation. This overlapped imaging study is no longer recommended. Also, multi-modal CT and MRI, including perfusion imaging, should not delay followed treatment.

About laboratory data obtaining from blood test, only the assessment of blood glucose is essential ${ }^{18)}$. Other tests include international normalized ratio(INR), activated partial thromboplastin time(aPTT), and platelet count, may be necessary in some circumstances if there is suspicion of coagulopathy. Given the extremely low risk of unsuspected abnormal platelet counts or coagulation studies in a population, IV alteplase treatment should not be delayed while waiting for hematologic or coagulation testing result if there is no reason to suspect an abnormal test. Baseline troponin and electrocardiogram assessment is recommended, but should not delay administration of IV alteplase.

\section{General medical supportive care}

Proper airway support and ventilator assistance are recommended for the patients have decreased consciousness. The goal of airway support is supplement of oxygen $>94 \%^{18,19)}$ of oxygen saturation. But, supplement of oxygen in non-hypoxic patients and any hyperbaric oxygen is not required ${ }^{19}$.

Optimal blood pressure level ensure best outcome is uncer$\operatorname{tain}^{23,25)}$. However, Powers et al. ${ }^{18)}$ recommends hypotension and hypovolemia should be corrected to maintain systemic perfusion. Patients who have elevated BP and eligible for treatment with IV alteplase, should their BP carefully lowered to systolic BP $<185$ $\mathrm{mmHg}$ and diastolic $\mathrm{BP}<110$ before IV fibrinolytic therapy is initiated, because the risk of hemorrhage after administration of alteplase is greater in patients with higher BP and in patients with more $\mathrm{BP}$ variability. Current recommendation includes maintain 
BP $<180 / 105 \mathrm{mmHg}$ after 24 hours of treatment.

Source of hyperthermia (temperature $>38^{\circ} \mathrm{C}$ ) should be identified and treated ${ }^{20)}$. Hypoglycemia (blood glucose $<60 \mathrm{mg} / \mathrm{dL}$ ) should be treated in patients with acute stroke ${ }^{18)}$.

\section{Intravenous alteplase}

After the introduction of IV thrombolysis for the treatment of acute stroke in the $1990 \mathrm{~s}^{10,28)}$, IV thrombolysis is medical treatment of choice of AIS. IV alteplase $(0.9 \mathrm{mg} / \mathrm{kg}$, maximum dose 90 mg over 60 minutes with initial 10\% of dose given as bolus over 1 minute) is recommended for standard treatment of AIS. Patients treated with IV alteplase should admit to stroke unit or intensive care unit for close monitoring. Measuring BP and perform neurological exam every 15 minutes during and after IV alteplase administration for 2 hours, then every 30 minutes for 6 hours, then hourly until 24 hours after IV alteplase treatment. During and after IV alteplase administration, delaying placement of nasogastric tube or indwelling bladder catheter is recommended if possible. Patients who treated within 3 hours of symptom onset or last known well time and medically eligible should be treated with IV alteplase. More importantly, exclusion criteria are strictly applied to patients. Contraindications of IV alteplase treatment ${ }^{18)}$; (1) patients who have an unclear time and/or unwitnessed symptom onset and whom the time last known well is $>3$ hours or 4.5 hours (2) CT image reveals intracranial hemorrhage (3) prior ischmic stroke within 3 months (4) severe head trauma within 3 months (5) intracranial/spinal surgery within 3 months (6) history of intracranial hemorrhage (7) GI malignancy or GI bleed within 21 days (8) coagulopathy (9) treatment with low-molecular-weight heparin (LMWH) within previous 24 hours (10) infective endocarditis (11) aortic arch dissection. Patients with other medical status including treatment with thrombin inhibitor, glycoprotein IIb/IIIa receptor inhibitor, intra-axial intracranial neoplasm is also potentially harmful to treat with IV alteplase.

In patients eligible for IV alteplase, benefit of therapy is time dependent, and treatment should be initiated as quickly as possible. Even if endovascular thrombectomy is considered, patients should receive IV alteplase therapy if eligible for criteria ${ }^{18)}$.

In former times, IV alterplase administration is applied to patients who treated within 3 hours of onset of stroke symptom or last known well time, because it's benefit and safety is not well established for patients treated over 3 hours of onset ${ }^{9,27)}$. However, Hacke et al. ${ }^{9)}$ describes benefit of IV alteplase administration to patients treated between 3 to 4.5 hours after onset. Current recommends IV alterplase treatment for selective patients who treated within 3 to 4.5 -hour-window ${ }^{18)}$. Resultingly, more patients should be treated with IV alterplase. The benefit of IV alteplase between 3 and 4.5 hours from symptom onset for patients with very severe stroke symptoms (NIHSS $>25$ ) is uncertain, other patients with NIHSS $<25$ should treat with IV alteplase in the concern of risks against possible benefits.

The most feared complication of this therapy is symptomatic intracerebral hemorrhage, which occurs up to $7 \%$ of treated patients $^{7}$. Therefore, physician should be prepared for such complication. Management of symptomatic intracranial bleeding during or after IV alteplase is ${ }^{18)}$; (1) stop alteplase infusion (2) hematologic evaluation includes complete blood cell clount(C$\mathrm{BC})$, prothrombin time(PT), INR, aPTT, fibrinogen level, type and cross-match (3) emergent head NCCT (4) cryoprecipitate 10 unit infused over 10-30minutes (5) tranexamic acid 1000mg IV infused over 10 minutes (6) hematology and neurosurgery consultation (6) general supportive therapy.

\section{Mechanical thrombectomy}

Endovascular treatment(EVT) could provide recanalization of occlusion, and likely to improve clinical outcome ${ }^{28}$. There are many techniques to achieve removal of clot, mechanical thrombectomy with stent retriever is recommended as the firstchoice ${ }^{18)}$. Mechanical thrombectomy is recommended when patients meet all of following; (1) pre-stroke modified Rankin $\mathrm{Scale}^{4)}$ (mRS, Table 2) score of 0 to 1 ; (2) causative occlusion of the internal carotid artery or MCA segment 1 (M1); (3) age $\geq 18$ years; (4) NIHSS score of $\geq 6$; (5) Alberta stroke program early CT score ${ }^{2}$ (ASPECTS, Fig. 1, Table 3) of $\geq 6$; and (6) treatment can be initiated within 6 hours of symptom onset. Goal

Table 2. Modified rankin scale (mRS)

\begin{tabular}{ll}
\hline Level & Description \\
\hline 0 & No symptoms \\
1 & No significant disability, despite symptoms ; able to perform all usual activity \\
2 & Slight disability; unable to perform all previous activities but able to look after own affairs without assistance \\
3 & Moderate disability; requires some help, but able to walk without assistance \\
4 & Moderate to severe disability; unable to walk without assistance and unable to attend to own bodily needs without assistance \\
5 & Severe disability; bedridden, incontinent and requires nursing care and attention
\end{tabular}


of mechanical thrombectomy should be reperfusion to modified Thrombolysis in Cerebral Infarction $^{26)}$ (mTICI, Table 4) grade $2 \mathrm{~b} / 3$ angiographic result.

Recent two randomized-controlled studies(RCTs) suggest that further expanded time window for mechanical thrombecto$m y^{1,15)}$. These RCTs demonstrate usefulness of newer imaging techniques (i.e. CT perfusion) for finding potentially salvageable region(penumbra $)^{28}$. Eligibility of DEFUSE $3 \mathrm{trial}^{1)} ;(1)$ initial infarct volume (ischemic core) of less than $70 \mathrm{ml}$; (2) ratio of volume of ischemic tissue to initial infarct volume of 1.8 or more;

Table 3. Alberta stroke program early CT score

\begin{tabular}{ll}
\hline Alberta Stroke Program Early CT Score (ASPECTS) \\
$\begin{array}{ll}\text { Subcortical structure } & \text { C, L, IC } \\
\text { MCA territory } & \text { I, M1, M2, M3, M4, M5, M6 }\end{array}$
\end{tabular}

Territory allotted 10 points, 1 points is subtracted for an area of early ischemic change(i.e. focal swelling, parenchymal hypoattenuation) for each defined regions.

Normal CT scan : ASPECTS value of 10 points

Score of 0 indicates diffuse cerebral ischemia throught the territory of MCA

C: caudate; L: lentiform; IC: internal capsule; MCA: middle cerebral artery; I: insula ribbon; M1-6: middle cerebral artery territory.
(3) absolute volume of potentially reversible ischemia (penumbra) of $15 \mathrm{ml}$ or more, and eligibility of DAWN trial ${ }^{15}$; (1) age $\geq$ 80 , NIHSS $\geq 10$, infarct volume $<21 \mathrm{ml}$; (2) age $<80$, NIHSS $\geq 10$, infarct volume $<31 \mathrm{ml}$; (3) age $<80$, NIHSS $\geq 20$, infarct volume $31 \mathrm{ml}$ to $<51 \mathrm{ml}$. If patients meet these criteria, mechanical thrombectomy is recommended to patients with AIS within 6 to 16 or 24 hours $^{18)}$.

\section{Antiplatelet agent}

Administration of antiplatelet agent (i.e. Aspirin) is recom-

Table 4. Modified treatment in cerebral infarction (mTICI) grade

\begin{tabular}{ll}
\hline Modified treatment in cerebral ischemia (mTICI) scale \\
$\begin{array}{ll}\text { Grade } 0 & \begin{array}{l}\text { No perfusion } \\
\text { Grade } 1\end{array} \\
\text { Antegrade reperfusion past the initial occlusion, but limited } \\
\text { distal branch filling with little or slow distal reperfusion }\end{array}$ \\
Grade 2a & $\begin{array}{l}\text { Antegrade reperfusion of less than half of the occluded target } \\
\text { artery previously ischemic territory (eg, in } 1 \text { major division } \\
\text { of the MCA and its territory) }\end{array}$ \\
Grade 2b & $\begin{array}{l}\text { Antegrade reperfusion of more than half of the previously } \\
\text { occluded target artery ischemic territory (eg, in } 2 \text { major } \\
\text { divisions of the MCA and their territories) }\end{array}$ \\
Grade 3 & $\begin{array}{l}\text { Complete antegrade reperfusion of the previously occluded } \\
\text { target artery ischemic territory, with absence of visualized }\end{array}$
\end{tabular}
occlusion in all distal branches
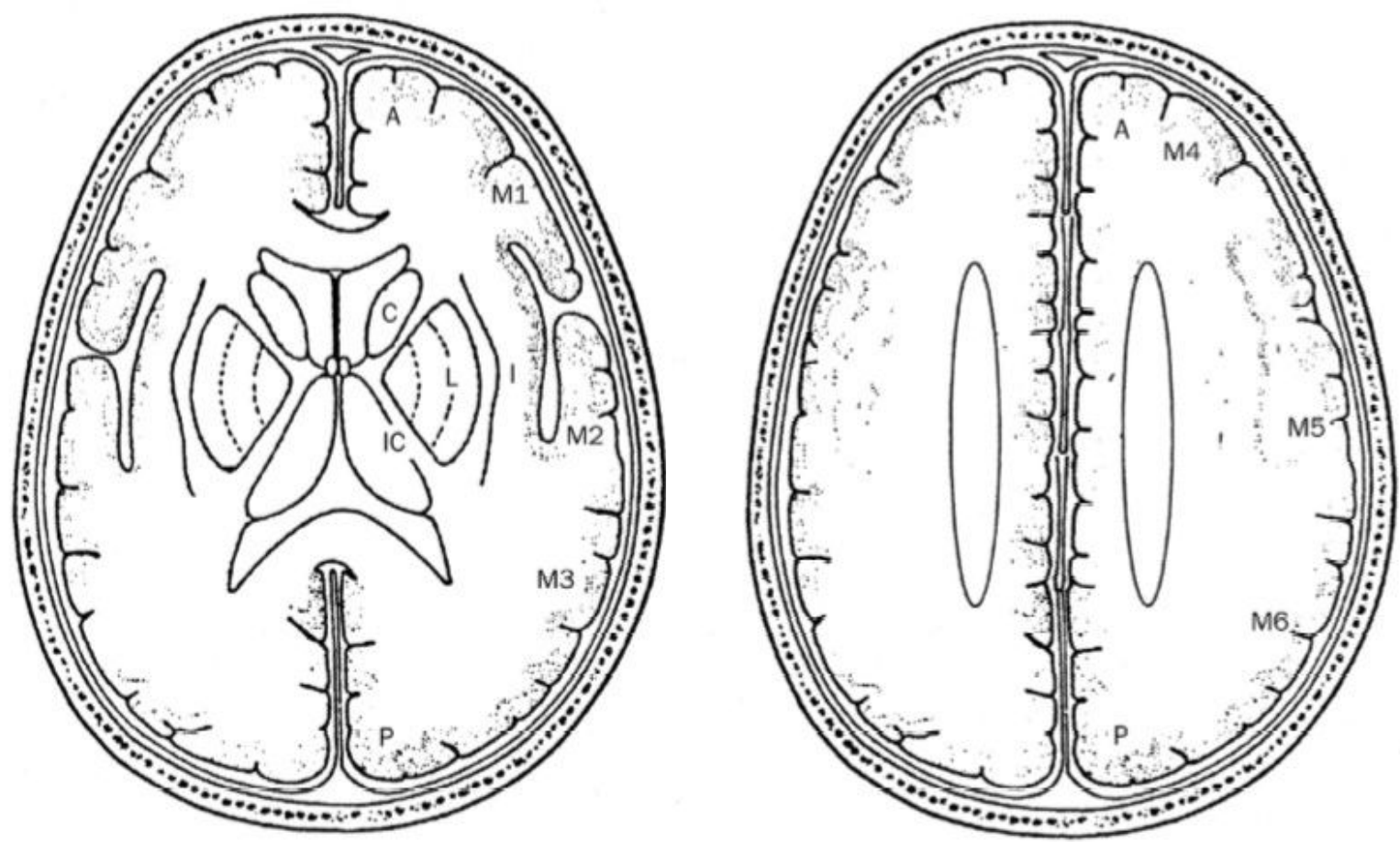

Fig. 1. Alberta stroke program early CT score (ASPECTS).

C: caudate; I: insula ribbon; L: lentiform; IC: internal capsule; A: anterior circulation; P: posterior circulation; M1-6: middle cerebral artery territory. 
mended in patients with AIS within 24 to 48 hours after onset. In former times, initial dose of $325 \mathrm{mg}$ of aspirin is recommended. However, Powers et al. recommends 160 to $300 \mathrm{mg}$ of dosage currently $^{18)}$.

\section{SUMMARY}

AIS is one of leading causes of disability and death, and patients suffer long-term care and rehabilitation. As described in article, although therapeutic time window has been expanded through decades, therapeutic time window is still narrow, and benefit from treatment is extremely time dependent. Adequate patient selection and urgent initiation of treatments are essential.

\section{CONFLICT OF INTEREST}

No potential conflict of interest relevant to this article was reported.

\section{REFERENCES}

1. Albers GW, Marks MP, Kemp S, Christensen S, Tsai JP, Ortega-Gutierrez S, et al. Thrombectomy for Stroke at 6 to 16 Hours with Selection by Perfusion Imaging. N Engl J Med 2018;378:708-718.

2. Barber PA, Demchuk AM, Zhang J, Buchan AM. Validity and reliability of a quantitative computed tomography score in predicting outcome of hyperacute stroke before thrombolytic therapy. ASPECTS Study Group. Alberta Stroke Programme Early CT Score. Lancet 2000;355:1670-1674.

3. Brazzelli M, Sandercock PA, Chappell FM, Celani MG, Righetti $\mathrm{E}$, Arestis N, et al. Magnetic resonance imaging versus computed tomography for detection of acute vascular lesions in patients presenting with stroke symptoms. Cochrane Database Syst Rev 2009; CD007424.

4. Broderick JP, Adeoye O, Elm J. Evolution of the Modified Rankin Scale and Its Use in Future Stroke Trials. Stroke 2017;48:2007-2012.

5. Cox AM, McKevitt C, Rudd AG, Wolfe CD. Socioeconomic status and stroke. Lancet Neurol 2006;5:181-188.

6. Feigin VL, Forouzanfar MH, Krishnamurthi R, Mensah GA, Connor M, Bennett DA, et al. Global and regional burden of stroke during 1990-2010: findings from the Global Burden of Disease Study 2010. Lancet 2014;383:245-254.

7. Goldstein JN, Marrero M, Masrur S, Pervez M, Barrocas AM, Abdullah A, et al. Management of thrombolysis-associated symptomatic intracerebral hemorrhage. Arch Neurol
2010;67:965-969.

8. Gomez CR. Editorial: Time is brain! J Stroke Cerebrovasc Dis 1992;3:1-2.

9. Hacke W, Kaste M, Bluhmki E, Brozman M, Davalos A, Guidetti D, et al. Thrombolysis with alteplase 3 to 4.5 hours after acute ischemic stroke. N Engl J Med 2008;359:1317-1329.

10. Haley EC Jr, Levy DE, Brott TG, Sheppard GL, Wong MC, Kongable GL, et al. Urgent therapy for stroke. Part II. Pilot study of tissue plasminogen activator administered 91-180 minutes from onset. Stroke 1992;23:641-645.

11. Hwang DY, Silva GS, Furie KL, Greer DM. Comparative sensitivity of computed tomography vs. magnetic resonance imaging for detecting acute posterior fossa infarct. J Emerg Med 2012;42:559-565.

12. Lyden P, Brott T, Tilley B, Welch KM, Mascha EJ, Levine S, et al. Improved reliability of the NIH Stroke Scale using video training. NINDS TPA Stroke Study Group. Stroke 1994;25:22202226.

13. Mathur S, Walter S, Grunwald IQ, Helwig SA, Lesmeister M, Fassbender K. Improving Prehospital Stroke Services in Rural and Underserved Settings With Mobile Stroke Units. Front Neurol 2019;10:159.

14. Messe SR, Khatri P, Reeves MJ, Smith EE, Saver JL, Bhatt DL, et al. Why are acute ischemic stroke patients not receiving IV tPA? Results from a national registry. Neurology 2016;87:1565-1574.

15. Nogueira RG, Jadhav AP, Haussen DC, Bonafe A, Budzik RF, Bhuva P, et al. Thrombectomy 6 to 24 Hours after Stroke with a Mismatch between Deficit and Infarct. N Engl J Med 2018;378:11-21.

16. Norrving B, Kissela B. The global burden of stroke and need for a continuum of care. Neurology 2013;80:S5-12.

17. Ovbiagele B, Goldstein LB, Higashida RT, Howard VJ, Johnston $\mathrm{SC}$, Khavjou OA, et al. Forecasting the future of stroke in the United States: a policy statement from the American Heart Association and American Stroke Association. Stroke 2013;44:2361-2375.

18. Powers WJ, Rabinstein AA, Ackerson T, Adeoye OM, Bambakidis NC, Becker K, et al. 2018 Guidelines for the Early Management of Patients With Acute Ischemic Stroke: A Guideline for Healthcare Professionals From the American Heart Association/American Stroke Association. Stroke 2018;49:e46-e110.

19. Roffe C, Nevatte T, Sim J, Bishop J, Ives N, Ferdinand P, et al. Effect of Routine Low-Dose Oxygen Supplementation on Death and Disability in Adults With Acute Stroke: The Stroke Oxygen Study Randomized Clinical Trial. JAMA 2017;318:11251135.

20. Saxena M, Young P, Pilcher D, Bailey M, Harrison D, Bellomo R, 
et al. Early temperature and mortality in critically ill patients with acute neurological diseases: trauma and stroke differ from infection. Intensive Care Med 2015;41:823-832.

21. Schroder J, Thomalla G. A Critical Review of Alberta Stroke Program Early CT Score for Evaluation of Acute Stroke Imaging. Front Neurol 2016;7:245.

22. Smith WS, Furlan AJ. Brief History of Endovascular Acute Ischemic Stroke Treatment. Stroke 2016;47:e23-26.

23. Vemmos KN, Tsivgoulis G, Spengos K, Zakopoulos N, Synetos A, Manios E, et al. U-shaped relationship between mortality and admission blood pressure in patients with acute stroke. J Intern Med 2004;255:257-265.

24. Wardlaw JM, Seymour J, Cairns J, Keir S, Lewis S, Sandercock P. Immediate computed tomography scanning of acute stroke is cost-effective and improves quality of life. Stroke 2004;35:2477-
2483.

25. Wohlfahrt P, Krajcoviechova A, Jozifova M, Mayer O, Vanek J, Filipovsky J, et al. Low blood pressure during the acute period of ischemic stroke is associated with decreased survival. J Hypertens 2015;33:339-345.

26. Zaidat OO, Yoo AJ, Khatri P, Tomsick TA, von Kummer R, Saver JL, et al. Recommendations on angiographic revascularization grading standards for acute ischemic stroke: a consensus statement. Stroke 2013;44:2650-2663.

27. Zhang B, Sun XJ, Ju CH. Thrombolysis with alteplase 4.5-6 hours after acute ischemic stroke. Eur Neurol 2011;65:170174.

28. Zivelonghi C, Tamburin S. Mechanical thrombectomy for acute ischemic stroke: the therapeutic window is larger but still "time is brain". Funct Neurol 2018;33:5-6. 